\title{
Methods for Body Composition Analysis in Adults
}

\author{
Göksun Ayvaz* and Ali Rıza Çimen
}

Gazi University Medical Faculty, Ankara, Turkey

\begin{abstract}
Fat and lean components of the body including total body fat, fat-free mass and total body water and ectopic fat accumulation are important constituents that link obesity, aging, and chronic disease to subsequent morbidity and mortality. The methodology of body composition is based on a series of models characterized by progressive levels of anatomical complexity. A commonly used example is five-level model: atomic, molecular, cellular, tissue-system, whole body. Each body composition analysis method targets a component or a subcomponent of the five-level model of body composition. The choice of body composition analysis method greatly depends on the question being asked, the setting where the measurement is performed and the availability of measuring devices. Body composition analysis methods vary in complexity and precision, and range from simple field based methods to more technically challenging, laboratory based methods. Although several methods have been developed to assess body composition, anthropometric indices are simple, safe and cheap measures to quantify obesity. Body mass index, calculated from height and weight, is the most frequently used, quickest and the easiest measure. As body mass index does not differentiate peripheral from abdominal obesity, the use of waist circumference and waist-to-hip ratio was proposed in various guidelines. Waist-to-height ratio is emerging as a new anthropometric index with a potential for global use in different ethnic groups and in adults and children. The minimum measurements to be made in the basal evaluation of overweight patients are weight, height and waist circumference to calculate body mass index and waist-to-height ratio.
\end{abstract}

Keywords: Body composition analysis, body composition, body weights and measures.

\section{INTRODUCTION}

In the last twenty years, there have been rapid improvements in body composition analysis. Progress has been made that increased the accuracy and easy applicability of the new and existing methods. In the last few decades, the prevalence of obesity increased alarmingly in the United States and other parts of the world $[1,2]$. In this regard, the prevalence of diseases associated with obesity such as diabetes also increased [1]. Intra-abdominal fat is implicated as an important independent risk factor for cardiovascular disease (CVD) [3]. Therefore, the quantification of obesity and the determination of body fat distribution are important for assessing future health risks. Prospective and cross-sectional studies have demonstrated that visceral obesity is closely related to impaired glucose tolerance [4], dyslipidemia [5], hypertension [6], insulin resistance [7,8] and metabolic syndrome [9]. Body composition analysis can be used in the evaluation of malnourished and thin people as well. Body composition measurements may be useful for identifying patients who do not have an increase in overall body fat, but who have an increase in visceral fat. The excessive fat tissue in aged people leads to weakness and feebleness of the body [10]. Elderly subjects have less muscle and bone mass, expanded extracellular fluid volume and reduced body cell mass compared to younger subjects [10]. Athletes and coaches use the body fat ratio and body composition data to optimize the nutrition and exercise programmes. Obesity

*Address correspondence to this author at the Division of Endocrinology and Metabolism, Department of Medicine, Gazi University Medical Faculty, Beşevler, 06500 Ankara, Turkey; Tel: (90) 31220258 29; E-mail: ayvaz@gazi.edu.tr management, haemodialysis, intensive care, sports medicine, geriatrics and military are among examples of clinical and nonclinical settings where body composition analysis is utilized.

The assessment of regional fat depots requires different methods from the measurement of total body fat. Accumulation of fat in non adipose tissue has been shown to be associated with obesity related adverse health outcomes. For instance, ectopic fat accumulation in skeletal muscle or liver is an independent risk factor for type $2 \mathrm{DM}$, degenerated muscle function and altered lipoprotein metabolism. Therefore, quantification of body fat tissue and its distribution are important in determination of disease risk, in clinical research and training, and its significance increases day-by-day. Simple anthropometric indices including body mass index (BMI), waist circumference (WC), waist-to-hip ratio (WHpR) and waist-to-height ratio (WHtR) are widely used in epidemiologic studies and in clinical practice due to their low expense and high convenience [11-14].

\section{BODY COMPOSITION MODELS}

Wang et al. [15] suggested that body composition could be divided into five levels: atomic, molecular, cellular, tissue-system and whole body and more than 30 body components can be evaluated in these five levels. As seen in Table 1, each group has subgroups. Body could be conceived as groups of constituents from each level, i.e. sum of all atoms, sum of all molecules, sum of all cells, sum of all tissues, sum of all organs and sum of all systems [16]. Simplified and expanded versions of the five-level model were suggested. A commonly used clinical model divides the 
Table 1. Five-Level Model of Body Composition [15] and Examples of Measurement Methods [16]

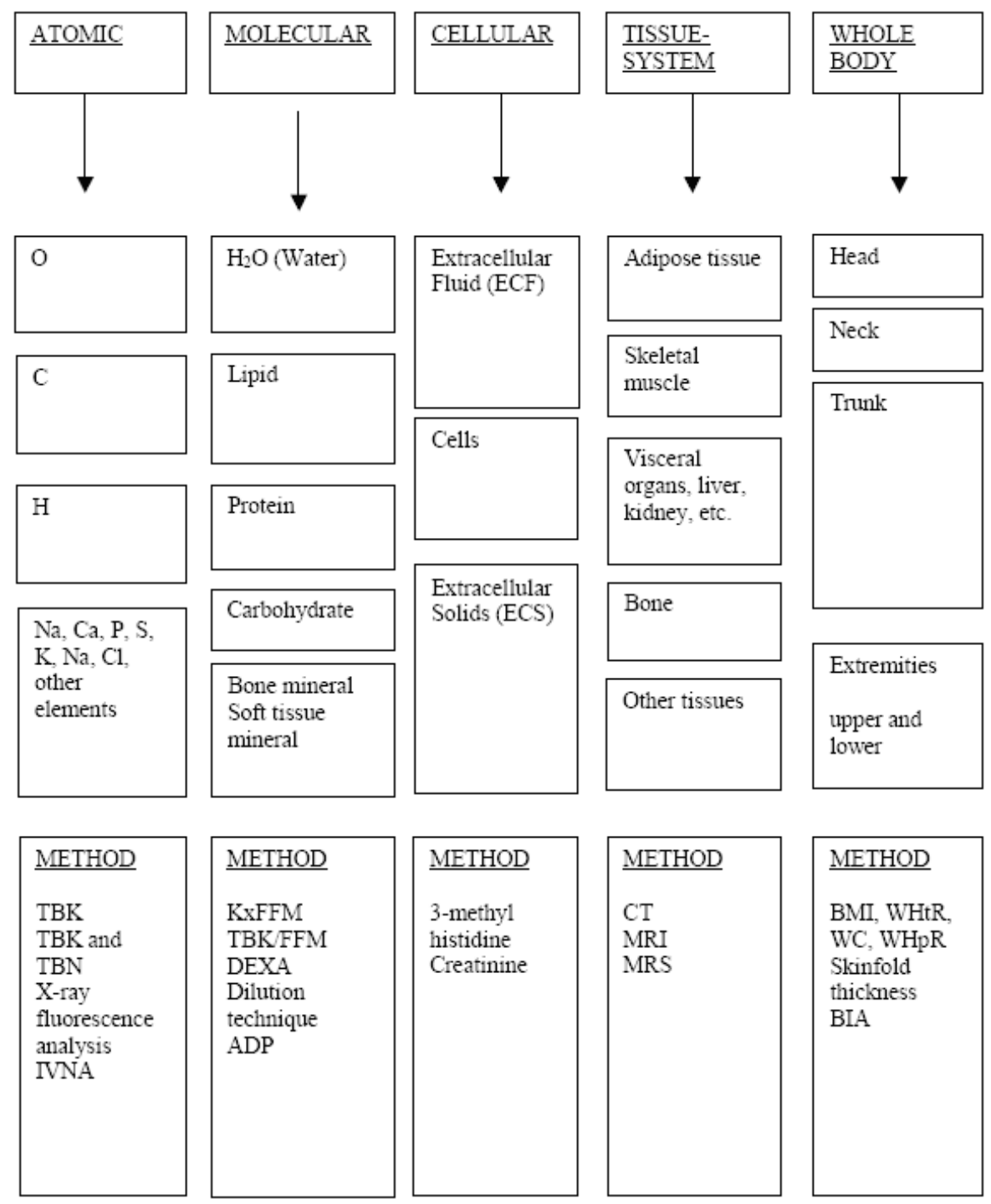

Abbreviations: ADP: air displacement plethysmography, BIA: bioelectric impedance, BMI: body mass index, CT: computed tomography, FFM: fat-free mass, IVNA: in vivo neutron activation analysis, MRI: magnetic resonance imaging, MRS: magnetic resonance spectroscopy, TBK: total body potassium, TBN: Total body nitrogen, WC: waist circumference, WHpR: waist-to-hip ratio, WHtR: waist-to-height ratio.

body into fat mass and fat-free mass (FFM). Table 1 outlines the five-level model of body composition and the measurement methods.

\subsection{Atomic Composition}

A human with approximately 70 kilograms of weight consists of $61 \%$ oxygen, $23 \%$ carbon, $10 \%$ hydrogen, $2.5 \%$ nitrogen and other atoms (such as calcium, phosphorus, sulphur, potassium, sodium, chlorine and magnesium) in less than $2 \%$ [16]. These 6 elements (oxygen, carbon, hydrogen, nitrogen, calcium, phosphorus) compose more than $98 \%$ of the body mass [15]. Whole body counting of ${ }^{40} \mathrm{~K}$ is used to measure potassium and neutron activation analysis is used for measuring $\mathrm{N}, \mathrm{H}, \mathrm{Ca}, \mathrm{Cl}, \mathrm{Na}$ and $\mathrm{P}$ levels [16]. Total body cell mass, body protein, body fat and trace element levels can be estimated with atomic composition analysis methods, such as X-ray fluorescence analysis and neutron activation analysis [16].

\subsection{Molecular Composition}

Chemical compositions of more than 100,000 substances ranging from simple to complex are identified in human body. Among these, water, lipids, proteins, carbohydrates and minerals are major molecules. Water makes $50 \%$ of body composition in women and $60 \%$ in men and $26 \%$ of this is extracellular and $34 \%$ is intracellular [17]. While it is possible that body fat ratio can be below $10 \%$ for athletes, it may be more than $50 \%$ for obese individuals. Proteins make $15 \%$ of the body composition and minerals make $5 \%[15$, 17]. The widely used two compartment model consists of fat mass and fat-free mass. FFM can be divided into water, protein and mineral [16].

\subsection{Cellular Composition}

Human body is formed by cells, extracellular liquid and extracellular solid substances. The body of an adult indivi- 
dual can be divided into four different cell categories: connective, epithelial, nervous, and muscular [17]. The fat cells, osteoblast, osteoclast and blood cells form the connective tissue [15]. Since potassium is the most significant cation of the intracellular compartment, body potassium content can be used as a body cell mass indicator [15]. 94\% of the extracellular liquid is water and is divided into two parts as interstitial fluid and intravascular plasma. Approximately 5\% of the individual's weight is formed by plasma liquid and $20 \%$ is formed by interstitial liquid [15].

\subsection{Tissue-Systems}

Whole body is formed by systems. Systems are formed by organs. Organs are formed by tissues. Tissues are formed by cells that have similar characteristics, functional capabilities and embryonic origin. Bone, muscle and fat tissue make up $75 \%$ of body weight [15]. Adipose tissue consists of adipocytes, extracellular fluid, collagenous and elastic fibers, fibroblasts, blood vessels and nerves [15, 16]. Adipose tissue can also be classified according to its distribution: subcutaneous, visceral, interstitial and yellow marrow [16]. The muscular tissue is formed by skeletal muscles, cardiac muscle and smooth muscle. Epithelial tissue covers the interior surface of empty body organs [15]. Combination of tissues forms organs. Major organ systems in the body are musculo-skeletal, skin, nervous, circulatory, respiratory, digestive, urinary, endocrine and reproductive systems. Adipose tissue, skeletal muscle, bone, viscera and blood make $85 \%$ of body weight [16].

\subsection{Whole-Body}

The whole body level is the highest level from the perspective of five level model of body composition and deals with external characteristics of human body: size, shape and weight. Height, segment lengths, waist circumference, skin fold thickness, body surface area, body volume, weight, body density and body mass index can be measured easily and noninvasively without potential of inflicting harm [15].

\section{BODY COMPOSITION ANALYSIS METHODS}

Cost, radiation use, accuracy and regional body mass calculability are determining factors for utility of these methods.

\subsection{Body Fat Derived from Body Density}

\subsubsection{Hydrodensitometry}

Flooding Volume Method: This method uses body weight and density for estimation of body fat. As it is somewhat cumbersome, it is not routinely used in clinical practice. It is accepted as the "gold standard" in body composition analysis. It is based on the Archimedes Principle, on the principle of the buoyancy of water [16]. According to this, since muscles and bones have higher density than fat, the body parts rich from muscle and bones are heavier in water. The weights of the body in and out of the water are measured to find the body density and with the help of the body density, the body fat percentage is calculated. Corrections for residual lung volume and for air in gastrointestinal tract are required [16]. An example of a body fat ratio equation is from Brozek and co-workers [18] and is as follows:

$$
\% \text { body fat }=[(4.57 / \text { body density })-4.142] \times 100 \text {. }
$$

\subsubsection{Air Displacement Plethysmography}

In air displacement plethysmography, air is used instead of water as in the underwater measurement and the procedure is carried through out of water [19]. BOD POD Body Composition System (Life Measurement Inc., Concord, CA, USA) uses air displacement plethysmography method to calculate the body volume of a patient seated inside a fibreglass chamber. There is a test and a reference chamber separated by a diaphragm. The subject is seated in the test chamber and the diaphragm is oscillated to provide a change in pressure and volume in test and reference chambers. Body volume is calculated from a formula that uses pressure and volume [19]. Proximity was found between the results of dual energy X-ray absorptiometry (DEXA), underwater weighting and air displacement methods [20].

\subsubsection{Three Dimensional Body Scanning}

Three dimensional body scanning and digital photographic anthropometry are new methods and are used for estimating body fat. With these methods, first body volume is found, and then body density and body fat ratio is calculated [21]. Three dimensional whole-body scanning uses either laser or white light projected onto the body with the reflection captured by cameras as a series of points (typically between 500,000 and one million) with $\mathrm{X}, \mathrm{Y}, \mathrm{Z}$ coordinates. Measurements can then be extracted from the scans using measurement extraction software. Their advantages are that they can be performed quickly and that they are well tolerated by patients. These methods still need the correction for residual lung volume. They could not get exactly validated as the main body composition measurement method. New developments are needed for routine use of these methods with accurate results [16].

\subsection{Dilution Technique}

\subsubsection{Total Body Water}

Total body water estimation is used frequently in body composition analysis. Total body water quantity and distribution is affected by many pathological and physiological conditions. Deuterium water, tritiated water and ${ }^{18} \mathrm{O}$-labelled water $\left(\mathrm{H}_{2}{ }^{18} \mathrm{O}\right)$ can be used for measurement [16]. The labelled water rapidly spreads within the body. The concentration of stable and labelled molecule is measured and total body water is calculated with the use of dilution principle. Dilution principle states that the volume of the compartment is equal to the amount of tracer added to the compartment divided by the concentration in the compartment [16, 22]. Total body water is measured with high accuracy rate with a 1 to $2 \%$ margin of error $[16,22]$.

\subsubsection{Intracellular and Extracellular Water}

Total body water can be divided into two as intracellular and extracellular water. In fact, intracellular body water cannot be measured. Intracellular body water is found by subtracting extracellular water from total body water. Particle substances such as bromide, chloride, thiocyanate, thiosulphate, sulphate, insulin, sucrose, and mannitol were 
tested and studied to measure extracellular water quantity [16]. Bromide is a frequently used particle element. It is given intravenously and it accumulates in the whole extracellular area in 4 hours and stays there for 24 hours [16]. The calculation is made with the use of urine and serum concentrations [23].

\subsubsection{Total Body Sodium and Potassium}

${ }^{22} \mathrm{Na}^{-}$or ${ }^{24} \mathrm{Na}^{-}$elements are used for total body sodium and ${ }^{42} \mathrm{~K}^{-}$is used for total body potassium. After the injection, 24 hours of urine is collected and radioactive material concentration, stable sodium or stable potassium concentrations are measured in plasma. The exchangeable sodium or potassium mass is measured with the correction of urine excretion [16].

\subsection{Whole-Body Counting and Neutron Activation Analysis}

\subsubsection{In Vivo Neutron Activation Analysis (IVNA)}

When a molecule enters a neutron zone, the atoms in the body give various types of nuclear reactions based on the energy of neutrons. In this way, neutron activation analysis can measure some elements in the body such as hydrogen, nitrogen, carbon, oxygen, sodium, calcium, chlorine and phosphorus [16]. Fast neutrons are the optimal ones with regard to tissue penetration. However, many IVNA reactions occur as thermal neutron reactions. Therefore, these systems involve a fast neutron source and utilize neutron thermalisation which provides fast reaction with tissue. The scans start from shoulders and extend to knee and require around half-an-hour to an hour [16]. Further details of IVNA can be found in the review by Mattsson and Thomas [16]. Major disadvantage of the IVNA is exposure to neutron radiation.

\subsubsection{Total Body Potassium Measurement (TBK)}

Potassium has a naturally occurring radioisotope in the body. ${ }^{40} \mathrm{~K}$ constitutes $0.0118 \%$ of all potassium in the body and decays with a half-life of $1.28 \times 10^{9}$ years [16]. By counting and measuring ${ }^{40} \mathrm{~K}$, total body potassium could be estimated. As potassium is an intracellular element, it is used to estimate body cell mass in adults with the following formula [16]:

$$
\text { Body cell mass }(\text { gram })=8.33 \times \text { TBK }(\mathrm{mmol})
$$

TBK value can be used to estimate fat-free mass [16]. FFM $(\mathrm{kg})=\mathrm{TBK}(\mathrm{mmol}) / 68.1$.

\subsection{DEXA}

The use of DEXA in the evaluation of body composition is becoming more widespread. The method is quick, has a relatively low cost and can be easily used in clinical studies and in various health care delivery locations. Radiation exposure from DEXA is considered small and is equivalent to $1-10 \%$ of a chest radiograph [21]. DEXA can also be used in large community-based studies. Due to the emission of tissue specific energy by X-rays, it directly measures body fat in line with the triple compartment model (fat tissue, bone and lean tissue) [24]. Following new developments in hardware and software, many recent studies have evaluated the differences among several DEXA scanners and DEXA was compared with other whole body composition analysis methods. The precision of DEXA is good with a coefficient of variation of $1 \%$ for bone mineral density and $2-3 \%$ for total body fat [16]. Different brands of DEXA scanners or different models from the same manufacturer show variations in measurements: up to $10 \%$ for fat mass, $6 \%$ for lean tissue and 3-6\% for body fat ratio [16]. Therefore longitudinal follow-up of a patient requires the use of the same DEXA scanner and caution is needed when comparing results from different DEXA scanners. DEXA results of fat mass are influenced by trunk thickness. This issue is important in obese subjects. As trunk thickness increases, the measurement error increases [21]. Although DEXA measurements produce quite detailed and fairly accurate results for fat tissue mass, FFM and bone mineral content, its disadvantage is that it cannot be repeated frequently due to radiation exposure [24].

\subsection{Imaging Techniques: Computed Tomography (CT) and Magnetic Resonance Imaging (MRI)}

CT and MRI are considered as the most accurate methods for quantification of skeletal muscle and adipose tissue and its distribution. These techniques are used for validation of other methods, like bioimpedance analysis [16]. Regional fat distribution is imaged reliably with MRI and CT. MRI and CT can also be used in the evaluation of the fat content of muscle and liver. Their utilization is increasing in body composition analysis.

\subsection{1. $C T$}

CT outlines the structure of internal organs. CT acquires images with computer analysis through the use of X-rays. CT differentiates tissues and organs based on their attenuation characteristics. Hounsfield unit is a measure of attenuation relative to water. The Hounsfield unit of water is 0 , air is -1000 , adipose tissue is between -190 and -30 , and skeletal muscle is between 30 and 100 [16]. Attenuation is related to tissue density and chemical composition. CT can visualize adipose tissue and with the help of software, it can quantify adipose tissue on cross-sectional images. Fat in adipose tissue, skeletal muscle, bone, visceral organs and brain can be measured [16]. In serial scans, the body fat measurement can be made with a margin of error of less than $1 \%$. As the attenuation value of fat is negative and muscle is positive, the lipid increase in muscular tissue decreases the attenuation of the muscle. It was observed that increased muscle lipid content is detected in muscle both chemically and histochemically in obesity and type 2 diabetes mellitus [25]. Low muscular attenuation values were found to be associated with decrease in muscular strength, low physical activity, insulin resistance and obesity in aged women and men [26]. The water content, which is another feature of the muscle, changes muscle attenuation value, and can be used to evaluate the degenerated muscle function and metabolism as a non invasive technique. Attenuation values are also used for fat storage in liver. As in the muscle, low attenuation values indicate low tissue density and increased lipid quantity. Moreover, hepatic glucose concentration influences the attenuation value and hepatic fat infiltration is evaluated relatively based on the spleen/liver ratio [16]. CT involves radiation exposure to patients, a major drawback in application for body composition analysis in routine clinical care. If less radiation exposure is desired, a measurement can 
be made in L1-L4 single scanning region. Visceral adipose tissue and subcutaneous adipose tissue can be measured at the L2-L3 and L4-L5 disc spaces [27].

\subsubsection{Quantitative $C T$}

Quantitative CT measures true volumetric bone mineral density and differentiates between trabecular and cortical components. Three dimensional high definition peripheral quantitative CT assesses bone mineral density, micro architecture and bone mechanics [21].

\subsubsection{MRI}

MRI requires a closed magnetic area and a relatively longer time for measurement than CT. Although the two imaging modalities are completely different in technique, their results in subcutaneous and visceral fat tissue assessment are similar. MRI has been used in the determination of quantity and distribution of fat and muscular tissue. MRI can measure the volume of subcutaneous, intra-abdominal, visceral and intramuscular adipose tissue. There is no X-ray exposure, making this method conveniently applicable to children and adolescents [16]. In standard $\mathrm{T}_{1}$-weighted images, fatty septas are seen in muscles. Low levels of muscle lipid content cannot be evaluated in $\mathrm{T}_{1}$-weighted series. However, in imaging carried out with selective high lipid signals, the muscular areas with high quality fat content are determined [25]. Conventional MRI is not useful for assessment of lipid and water quantity in skeletal muscle [21]. Chemical shift imaging methods have been used to differentiate water and fat signals in MRI, enabling to quantify water and fat contents of skeletal muscle [16]. It is possible to perform whole body MRI to determine body composition and to assess the effect of weight loss treatment on body fat distribution and quantity [16].

\subsubsection{Magnetic Resonance Spectroscopy (MRS)}

MRS is a new non invasive method and can measure the fat tissue content and distribution both in adipose tissue and in non-adipose tissue $[16,25]$. The lipid content of the skeletal muscle can be measured with MRS [21]. Volume localized magnetic resonance spectroscopy is a recently developed method and the intra-myocellular and extramyocellular lipid differentiation can be made in vivo. Intramyocellular lipid levels can be quantified by ${ }^{1} \mathrm{H}$-MRS [28]. The differentiation of these two lipid components can be made with the differentiation of lipid- $\mathrm{CH}_{2}$-regions with resonance. This method was used to explore the relation between intra-myocellular lipid and insulin resistance and the influence of exercise on intra-myocellular lipid content [29]. Hepatic triglyceride content can be measured by ${ }^{13} \mathrm{C}$ MRS [30]. However, there are still problems with the method in accurate determination of the lipid amount. The spatial distribution or the exact lipid concentration cannot be evaluated in muscles [25]. The margin of error in this method is $6 \%$ in the assessment of intra-myocellular lipid content [28].

\subsubsection{Quantitative Magnetic Resonance}

Quantitative magnetic resonance uses the differences in nuclear magnetic resonance properties of hydrogen atoms in organic and inorganic properties to fractionate signals originating from fat, lean tissue and water [21]. This method is in the process of development and needs comparison and validation with established methods of body composition.

\subsubsection{Positron Emission Tomography}

Fluorodeoxyglucose positron emission tomography has its place in research setting. Studies that utilized positron emission tomography showed the localization of brown adipose tissue in supraclavicular, paravertebral, mediastinal, paraaortic and suprarenal areas and in neck regions in adults, and detected reductions in insulin stimulated glucose uptake in skeletal muscle and adipose tissue in abdominally obese subjects [21].

\subsection{Bioimpedance Analysis (BIA)}

Bioelectric impedance is used for calculating total body water, FFM and fat tissue mass. This method is based on the principle that the conductivity of body water varies in different compartments. BIA measures the impedance to an applied small electric current as it passes through the body's water pool [21]. From an established equation that uses the measured impedance value and height, total body water is estimated [16]. Then fat-free mass is calculated assuming $73 \%$ of humans' fat-free mass is water [21]. Fat mass is found by subtracting fat-free mass from body weight. Singlefrequency BIA is capable of assessing TBW and FFM but not intracellular and extracellular water [21]. Multi frequency BIA or bioimpedance spectroscopy can measure total body water as intracellular and extracellular water. Multi segmental BIA can analyse composition of extremities as well as trunk [21].

Bioelectric impedance is non invasive and relatively inexpensive but its methods are indirect and often empirical and may not be accurate in patients who are at the extremes of abnormal morphology. Generally speaking, it produces similar results with body fat measurements obtained with other methods. Two types of impedance measurement methods were developed. The first one is the medical impedance measurements. Medical impedance meters are used in supine position with four gel-type electrodes, two voltage and two current ones, pasted on the right foot and wrist. The second one is classified as body fat analyzers. Body fat analyzers are for both health care professionals and the general public and are also called leg-to-leg or foot-tofoot impedance meters. First introduced by Tanita Corporation (Tokyo, Japan), body fat analyzers consist of a body scale with four contact reusable electrodes under the feet. They are portable and used in upright position. Some of them calculate total body fat ratio, fat mass and also fat ratio and fat mass of the extremities [31]. Body fat analyzers have relatively low costs compared to other more sophisticated imaging modalities and can be rapidly and easily applied. Although measurements with impedance method are used frequently, they involve some limitations. When measurement is made with this method, a slight change in the place of electrodes can produce differences in results. The measurements can show $2 \%$ variability in different days.

The validity of bioimpedance measurement was verified by comparison with DEXA [32-34]. More advanced BIA techniques were developed like bioelectrical spectroscopy, segmental-BIA, localized bioelectrical impedance analysis and bioelectrical impedance vector analyses. 


\subsection{Anthropometry}

\subsubsection{Anthropometric Measurements}

Many anthropometric measurements can be used in the regional and total body evaluations. Anthropometric indices are simple, safe and cost-free way to quantify the degree of obesity. Because of the lack of cheap and convenient methods for directly assessing body composition, anthropometric indices are often used as surrogates for assessing obesity and body fat distribution. BMI is the most widely used anthropometric index and gives information on fat mass and lean mass [35]. Measurement of WC is recommended by the United States National Cholesterol Education Program for assessment of central obesity, whereas World Health Organization recommends WHpR for the same purpose [11, 35]. All of the above mentioned anthropometric indices have been found to be associated with all cause mortality, diabetes mellitus, cardiovascular morbidity and mortality in prospective studies [36-43]. Some authors proposed WHtR as the best anthropometric index to predict CVD risk and the metabolic syndrome [44-47].

As given in Table 2, World Health Organization recommends using body mass index (BMI) to define obesity [35]. $\mathrm{BMI}$ is calculated by dividing body weight in $\mathrm{kg}$ to square of height in meter.

Table 2. Classification of Obesity Based on Body Mass Index [35]

\begin{tabular}{|c|c|c|c|}
\hline Weight Class & Obesity Class & BMI $\left(\mathrm{kg} / \mathrm{m}^{2}\right)$ & Disease Risk \\
\hline Low weight & - & $<18.5$ & Increased \\
\hline Normal & - & $18.5-24.9$ & Normal \\
\hline Overweight & - & $25.0-29.9$ & Increased \\
\hline Obese & I & $30.0-34.9$ & High \\
\hline Obese & II & $35.0-39.9$ & Very high \\
\hline Morbid obese & III & $\geq 40.0$ & Extremely high \\
\hline
\end{tabular}

Age, sex, race and body structure should be considered when BMI is interpreted. Gallagher et al. [48] studied the influence of age, race and sex on the relationship of BMI with body fat percentage. Their study included white and black men and women from New York City and showed that the relation of BMI with body fat was influenced by age and sex, but no relation was found with ethnicity [48].

Abdominal obesity is generally assessed by either WC or WHpR. WHtR is emerging as a new anthropometric index with a potential for global application [49]. Waist measurement is best undertaken using a specially designed tape measure. Patients should be asked not to hold their stomach in and a constant-tension, spring-loaded tape device reduces errors from over tightening. The tape should be placed around the abdomen at the midpoint between the lower rib margin and iliac crest (right or left protrusions of the pelvic bone) and the measurement should be made horizontally at the end of gentle expiration. In very obese subjects and those who have lost considerable weight, the measurement is not reliable because of sagging of abdominal fat from its usual place at umbilicus.

Prospective and case-controlled studies indicate that even with a 'normal' BMI, those with an elevated WC or WHpR can have a two- to threefold increase in CVD risk and premature death $[41,50,51]$. It is believed that abdominal obesity reflects an increased amount of intra-abdominal fat including visceral adipose tissue. WC was associated with increased diabetes risk, independent of other factors [52]. The most commonly used cut-offs among Caucasians for WC are $102 \mathrm{~cm}$ for men and $88 \mathrm{~cm}$ for women [11]. The WHpR cut-off is 0.95 for men and 0.80 for women [35]. However, these cut-offs have been based on studies in populations of European origin. A number of commentaries have raised the issue that these anthropometric cut-offs may not be appropriate for non-Europeans [53, 54]. There is no universal cut-off value that can be applied worldwide, and a country-specific value should be considered taking into account the purposes and resources [55]. WHtR has the advantage of having the same cut-offs across different populations and geographic areas [49].

\subsubsection{Skin Fold Thickness Measurement}

Skin fold thickness is correlated with body fat percentage and this association is used for estimating body fat ratio. Since subcutaneous tissue contains varying amounts of fat in different regions, measurements from various areas should be made for an accurate determination. As the percentage of subcutaneous tissue to total body fat varies, this fact needs to be considered when making the evaluation. When body fat is estimated with skin fold thickness, there is a margin of error between $3 \%$ and $11 \%$ [56]. Although skin fold thickness measurement is easy to make, the measurement should be done by trained and experienced people for accurate results. The procedure may produce different results depending on the individual who conduct it. The use of different measurement tools, measurement from anatomically different places and the skin grapping technique play a role in varying results. Some authors do not recommend its use for fat percentage estimates in morbidly obese individuals. Skin fold thickness measurement is one of the most frequently used methods because of the easiness of its application and low costs, despite all disadvantages [16].

\subsection{Tissue Biopsy}

Tissue evaluation through conducting a biopsy: Per cutaneous muscle biopsy can be used in the research setting for evaluation in exercise physiology, clinical nutrition, obesity and in various disease states and pathophysiologies. Triglyceride measurement is used as a routine procedure in biochemical extraction and biopsy samples. In human biopsies, the amount of lipid in skeletal muscle cells can be measured histopathologically with oil red O staining method $[57,58]$.

\section{CONCLUSIONS}

The methodology of body composition is based on a series of models characterized by progressive levels of anatomical complexity. A commonly used example is fivelevel model: atomic, molecular, cellular, tissue-system, 
whole body [15]. Each body composition analysis method targets a component or a subcomponent of the five-level model of body composition. Misjudgement and errors can happen if a measurement method makes assumptions related to body composition proportions and characteristics in a sampled group of subjects and if these proportions and characteristics are not valid across different populations [21]. The most commonly used methods are BIA, dilution techniques, air displacement plethysmography, DEXA, CT, MRI and MRS [16]. Three dimensional body scanning and quantitative magnetic resonance are recently developed techniques. The routine use of CT and MRI cannot be recommended because of high costs and exposure to radiation for CT. Body fat analyzers are designed to be used with plantar electrodes, have low costs and can be rapidly and easily applied. Selection of the technique for body composition measurement depends on the question being asked, the availability of measuring devices, the setting where the measurement is performed, the applicability of body composition analysis results for clinical decision making and to the study hypothesis. There is no single measurement method that is error free. The minimum measurements to be made in basal evaluations in overweight patients are weight, height and waist circumference to calculate BMI and WHtR.

\section{ABBREVIATIONS}

$\begin{array}{ll}\text { BIA } & =\text { Bioelectrical impedance analysis } \\ \text { BMI } & =\text { Body mass index } \\ \mathrm{CT} & =\text { Computed tomography } \\ \text { CVD } & =\text { Cardiovascular disease } \\ \text { DEXA } & =\text { Dual energy X-ray absorptiometry } \\ \text { FFM } & =\text { Fat-free mass } \\ \text { IVNA } & \text { In vivo neutron activation analysis } \\ \text { MRI } & =\text { Magnetic resonance imaging } \\ \text { MRS } & \text { Magnetic resonance spectroscopy } \\ \text { TBK } & =\text { Total body potassium } \\ \text { TBN } & =\text { Total body nitrogen } \\ \text { WC } & =\text { Waist circumference } \\ \text { WHpR } & \text { Waist-to-hip ratio } \\ \text { WHtR } & =\text { Waist-to-height ratio }\end{array}$

\section{REFERENCES}

[1] Estimated county-level prevalence of diabetes and obesity - United States, 2007. Morb Mortal Wkly Rep 2009; 58: 1259-63.

[2] Khang YH, Yun SC. Trends in general and abdominal obesity among Korean adults: findings from 1998, 2001, 2005, and 2007 Korea National Health and Nutrition Examination Surveys. J Korean Med Sci 2010; 25: 1582-8.

[3] Mahabadi AA, Massaro JM, Rosito GA, et al. Association of pericardial fat, intrathoracic fat, and visceral abdominal fat with cardiovascular disease burden: the Framingham Heart Study. Eur Heart J 2009; 30: 850-6.

[4] Hayashi T, Boyko EJ, Leonetti DL, et al. Visceral adiposity and the risk of impaired glucose tolerance: a prospective study among Japanese Americans. Diabetes Care 2003; 26: 650-5.
[5] Pascot A, Lemieux S, Lemieux I, et al. Age-related increase in visceral adipose tissue and body fat and the metabolic risk profile of premenopausal women. Diabetes Care 1999; 22: 1471-8.

[6] Sironi AM, Gastaldelli A, Mari A, et al. Visceral fat in hypertension: influence on insulin resistance and beta-cell function. Hypertension 2004; 44: 127-33.

[7] Wagenknecht LE, Langefeld CD, Scherzinger AL, et al. Insulin sensitivity, insulin secretion, and abdominal fat: the Insulin Resistance Atherosclerosis Study (IRAS) Family Study. Diabetes 2003; 52: 2490-6.

[8] Goodpaster BH, Krishnaswami S, Resnick H, et al. Association between regional adipose tissue distribution and both type 2 diabetes and impaired glucose tolerance in elderly men and women. Diabetes Care 2003; 26: 372-9.

[9] Carr DB, Utzschneider KM, Hull RL, et al. Intra-abdominal fat is a major determinant of the National Cholesterol Education Program Adult Treatment Panel III criteria for the metabolic syndrome. Diabetes 2004; 53: 2087-94

[10] Baumgartner RN. Body composition in healthy aging. Ann N Y Acad Sci 2000; 904: 437-48.

[11] Executive Summary of The Third Report of The National Cholesterol Education Program (NCEP) Expert Panel on Detection, Evaluation, And Treatment of High Blood Cholesterol In Adults (Adult Treatment Panel III). JAMA 2001; 285: 2486-97.

[12] Lemieux S, Prud'homme D, Bouchard C, Tremblay A, Despres JP. A single threshold value of waist girth identifies normal-weight and overweight subjects with excess visceral adipose tissue. Am J Clin Nutr 1996; 64: 685-93.

[13] Megnien JL, Denarie N, Cocaul M, Simon A, Levenson J. Predictive value of waist-to-hip ratio on cardiovascular risk events. Int J Obes Relat Metab Disord 1999; 23: 90-7.

[14] Lee CM, Huxley RR, Wildman RP, Woodward M. Indices of abdominal obesity are better discriminators of cardiovascular risk factors than BMI: a meta-analysis. J Clin Epidemiol 2008; 61: 64653.

[15] Wang ZM, Pierson RN, Jr., Heymsfield SB. The five-level model: a new approach to organizing body-composition research. Am J Clin Nutr 1992; 56: 19-28.

[16] Mattsson S, Thomas BJ. Development of methods for body composition studies. Phys Med Biol 2006; 51: R203-28.

[17] Wang Z, Shen W, Withers RT, Heymsfield SB. Multicomponent molecular-level models of body composition analysis. In: Heymsfield SB, Lohman TG, Wang Z, Going ZB, editors. Human Body Composition. 2nd ed. Champaign, IL: Human Kinetics; 2005. p. 163-76.

[18] Brozek J, Grande F, Anderson JT, Keys A. Densitometric Analysis of Body Composition: Revision of Some Quantitative Assumptions. Ann N Y Acad Sci 1963; 110: 113-40.

[19] Dempster P, Aitkens S. A new air displacement method for the determination of human body composition. Med Sci Sports Exerc 1995; 27: 1692-7.

[20] Nunez C, Kovera AJ, Pietrobelli A, et al. Body composition in children and adults by air displacement plethysmography. Eur $\mathrm{J}$ Clin Nutr 1999; 53: 382-7.

[21] Lee SY, Gallagher D. Assessment methods in human body composition. Curr Opin Clin Nutr Metab Care 2008; 11: 566-72.

[22] Edelman IS, Olney JM, James AH, Brooks L, Moore FD. Body Composition: Studies in the Human Being by the Dilution Principle. Science 1952; 115: 447-54.

[23] Vaisman N, Pencharz PB, Koren G, Johnson JK. Comparison of oral and intravenous administration of sodium bromide for extracellular water measurements. Am J Clin Nutr 1987; 46: 1-4.

[24] Andreoli A, Scalzo G, Masala S, Tarantino U, Guglielmi G. Body composition assessment by dual-energy X-ray absorptiometry (DXA). Radiol Med 2009; 114: 286-300.

[25] Goodpaster BH. Measuring body fat distribution and content in humans. Curr Opin Clin Nutr Metab Care 2002; 5: 481-7.

[26] Goodpaster BH, Kelley DE, Thaete FL, He J, Ross R. Skeletal muscle attenuation determined by computed tomography is associated with skeletal muscle lipid content. J Appl Physiol 2000; 89: 104-10.

[27] Bray GA, Jablonski KA, Fujimoto WY, et al. Relation of central adiposity and body mass index to the development of diabetes in the Diabetes Prevention Program. Am J Clin Nutr 2008; 87: 12128 
[28] Boesch C, Slotboom J, Hoppeler H, Kreis R. In vivo determination of intra-myocellular lipids in human muscle by means of localized 1H-MR-spectroscopy. Magn Reson Med 1997; 37: 484-93.

[29] White LJ, Ferguson MA, McCoy SC, Kim H. Intramyocellular lipid changes in men and women during aerobic exercise: a (1) $\mathrm{H}-$ magnetic resonance spectroscopy study. J Clin Endocrinol Metab 2003; 88: 5638-43.

[30] Petersen KF, West AB, Reuben A, Rothman DL, Shulman GI. Noninvasive assessment of hepatic triglyceride content in humans with 13C nuclear magnetic resonance spectroscopy. Hepatology 1996; 24: 114-7.

[31] Nunez C, Gallagher D, Visser M, Pi-Sunyer FX, Wang Z, Heymsfield SB. Bioimpedance analysis: evaluation of leg-to-leg system based on pressure contact footpad electrodes. Med Sci Sports Exerc 1997; 29: 524-31.

[32] Jaffrin MY. Body composition determination by bioimpedance: an update. Curr Opin Clin Nutr Metab Care 2009; 12: 482-6.

[33] Jebb SA, Cole TJ, Doman D, Murgatroyd PR, Prentice AM. Evaluation of the novel Tanita body-fat analyser to measure body composition by comparison with a four-compartment model. Br J Nutr 2000; 83: 115-22.

[34] Jebb SA, Siervo M, Murgatroyd PR, Evans S, Fruhbeck G, Prentice AM. Validity of the leg-to-leg bioimpedance to estimate changes in body fat during weight loss and regain in overweight women: a comparison with multi-compartment models. Int J Obes (Lond) 2007; 31: 756-62.

[35] WHO. Obesity: preventing and managing the global epidemic. Report of a WHO consultation on obesity. World Health Organization Technical Report Series WHO/NUT/NCD/981. Geneva: WHO 1997.

[36] Simpson JA, MacInnis RJ, Peeters A, Hopper JL, Giles GG, English DR. A comparison of adiposity measures as predictors of all-cause mortality: the Melbourne Collaborative Cohort Study. Obesity (Silver Spring) 2007; 15: 994-1003.

[37] Batty GD, Kivimaki M, Smith GD, Marmot MG, Shipley MJ. Obesity and overweight in relation to mortality in men with and without type 2 diabetes/impaired glucose tolerance: the original Whitehall Study. Diabetes Care 2007; 30: 2388-91.

[38] Bigaard J, Tjonneland A, Thomsen BL, Overvad K, Heitmann BL, Sorensen TI. Waist circumference, BMI, smoking, and mortality in middle-aged men and women. Obes Res 2003; 11: 895-903.

[39] Welborn TA, Dhaliwal SS, Bennett SA. Waist-hip ratio is the dominant risk factor predicting cardiovascular death in Australia. Med J Aust 2003; 179: 580-5.

[40] Visscher TL, Seidell JC, Molarius A, van der Kuip D, Hofman A, Witteman JC. A comparison of body mass index, waist-hip ratio and waist circumference as predictors of all-cause mortality among the elderly: the Rotterdam study. Int J Obes Relat Metab Disord 2001; 25: 1730-5.

[41] Yusuf S, Hawken S, Ounpuu S, et al. Obesity and the risk of myocardial infarction in 27,000 participants from 52 countries: a case-control study. Lancet 2005; 366: 1640-9.

[42] Katzmarzyk PT, Craig CL. Independent effects of waist circumference and physical activity on all-cause mortality in Canadian women. Appl Physiol Nutr Metab 2006; 31: 271-6.
[43] Folsom AR, Kushi LH, Anderson KE, et al. Associations of general and abdominal obesity with multiple health outcomes in older women: the Iowa Women's Health Study. Arch Intern Med 2000; 160: 2117-28.

[44] Hsieh SD, Muto T. The superiority of waist-to-height ratio as an anthropometric index to evaluate clustering of coronary risk factors among non-obese men and women. Prev Med 2005; 40: 216-20.

[45] Schneider HJ, Glaesmer H, Klotsche J, et al. Accuracy of anthropometric indicators of obesity to predict cardiovascular risk. J Clin Endocrinol Metab 2007; 92: 589-94.

[46] Fuchs FD, Gus M, Moreira LB, et al. Anthropometric indices and the incidence of hypertension: a comparative analysis. Obes Res 2005; 13: 1515-7.

[47] Hsieh SD, Muto T. Metabolic syndrome in Japanese men and women with special reference to the anthropometric criteria for the assessment of obesity: Proposal to use the waist-to-height ratio. Prev Med 2006; 42: 135-9.

[48] Gallagher D, Visser M, Sepulveda D, Pierson RN, Harris T, Heymsfield SB. How useful is body mass index for comparison of body fatness across age, sex, and ethnic groups? Am J Epidemiol 1996; 143: 228-39.

[49] Ashwell M, Hsieh SD. Six reasons why the waist-to-height ratio is a rapid and effective global indicator for health risks of obesity and how its use could simplify the international public health message on obesity. Int J Food Sci Nutr 2005; 56: 303-7.

[50] Rexrode KM, Carey VJ, Hennekens CH, et al. Abdominal adiposity and coronary heart disease in women. JAMA 1998; 280: 1843-8.

[51] Pischon T, Boeing H, Hoffmann K, et al. General and abdominal adiposity and risk of death in Europe. N Engl J Med 2008; 359: 2105-20.

[52] Relationship of body size and shape to the development of diabetes in the diabetes prevention program. Obesity (Silver Spring) 2006; 14: 2107-17.

[53] Misra A. Revisions of cutoffs of body mass index to define overweight and obesity are needed for the Asian-ethnic groups. Int J Obes Relat Metab Disord 2003; 27: 1294-6.

[54] Shiwaku K, Anuurad E, Enkhmaa B, Kitajima K, Yamane Y. Appropriate BMI for Asian populations. Lancet 2004; 363: 1077.

[55] Alberti KG, Eckel RH, Grundy SM, et al. Harmonizing the metabolic syndrome: a joint interim statement of the International Diabetes Federation Task Force on Epidemiology and Prevention; National Heart, Lung, and Blood Institute; American Heart Association; World Heart Federation; International Atherosclerosis Society; and International Association for the Study of Obesity. Circulation 2009; 120: 1640-5.

[56] Wang J, Thornton JC, Kolesnik S, Pierson RN, Jr. Anthropometry in body composition. An overview. Ann N Y Acad Sci 2000; 904: 317-26.

[57] Goodpaster BH, He J, Watkins S, Kelley DE. Skeletal muscle lipid content and insulin resistance: evidence for a paradox in endurance-trained athletes. J Clin Endocrinol Metab 2001; 86: 5755-61.

[58] Goodpaster BH, Theriault R, Watkins SC, Kelley DE. Intramuscular lipid content is increased in obesity and decreased by weight loss. Metabolism 2000; 49: 467-72.

(C)Ayvaz and Çimen; Licensee Bentham Open.

This is an open access article licensed under the terms of the Creative Commons Attribution Non-Commercial License (http: //creativecommons.org/licenses/by$\mathrm{nc} / 3.0 /$ ), which permits unrestricted, non-commercial use, distribution and reproduction in any medium, provided the work is properly cited. 